\title{
Analisis Potensi Program Studi Kimia Menuju Akreditasi Internasional Oleh Royal Society Of Chemistry (RSC)
}

\section{La Ode Sumarlin ${ }^{1}$, Ade Candra ${ }^{2}$, Nurhasni ${ }^{3}$}

${ }^{1}$ Fakultas Sains dan Teknologi UIN Syarif Hidayatullah Jakarta sumarlin@uinjkt.ac.id

${ }^{2}$ Fakultas Sains dan Teknologi UIN Syarif Hidayatullah Jakarta ade.candra@uinjkt.ac.id

${ }^{3}$ Fakultas Sains dan Teknologi UIN Syarif Hidayatullah Jakarta nurhasni@uinjkt.ac.id

\begin{abstract}
Abstrak
Industrial Revolution 4.0 (IR 4.0) telah memberikan dorongan baru untuk transformasi dan peningkatan kualitas Pendidikan Tinngi (PT). Salah satu upaya yang dilakukan adalah pengakuan terhadap kualitas pengelolaan PT melalui proses akreditasi baik secara nasional maupun internasional. Fokus utama bahan kajian adalah identifikasi kesiapan PS Kimia Fakultas Sains dan Teknologi UIN Syarif Hidayatullah Jakarta menuju akreditasi RSC. Data yang diperoleh berasal dari data angket yang disebarkan, wawancara langsung, studi pustaka, penilaian lapangan dan Focus Group Discussion (FGD). Data diolah dari berbagai sumber tersebut dan dianalisis. Hasil analisis menunjukkan bahwa PS kimia secara umum telah mengikuti perkembangan revolusi industri 4.0 dan juga cukup kondusif baik dari sisi dukungan sumberdaya dengan kemampuan penggunaan teknologi informasi yang baik. Selain itu kriteria akreditasi RSC pada beberapa kunci persyaratan utama telah dapat dicapai oleh PS Kimia, namun demikian perlu optimalisasi dalam beberapa faktor kunci lainnya khususnya aspek kurikulum dan Benchmarking. Secara rinci perlu dilakukan pula berbagai berbagai langkah tindaklanjut seperti identifikasi beberapa aspek perbaikan kurikulum dan proses pembelajaran berbasis OBE (Outcome Base Education), evaluasi belajar dan skill mahasiswa dan evaluasi praktikum secara menyeluruh sesuai standar RSC.
\end{abstract}

Kata Kunci: Akreditasi, Kimia, Royal Society of Chemistry 


\section{Abstract}

Industrial Revolution 4.0 (IR 4.0) has provided a new impetus for the transformation and improvement of the quality of Higher Education (PT). One of the efforts made is the recognition of the quality of PT management through an accreditation process both nationally and internationally. One of the international accreditation institutions specific to the Chemistry Study Program (PS) is the Royal Society of Chemistry (RSC). The main focus of the study material is the identification of the readiness of the Chemistry Study Program at the Faculty of Science and Technology UIN Syarif Hidayatullah Jakarta towards RSC accreditation. The data obtained came from questionnaire data that was distributed, direct interviews, literature studies, field assessments and Focus Group Discussions (FGD). The data were processed from various sources and analyzed. The results of the analysis show that chemical PS in general has followed the development of the industrial revolution 4.0 and is also quite conducive both in terms of resource support and the ability to use good information technology. In addition, the RSC accreditation criteria on several key requirements have been achieved by Chemistry Study Program, however, it needs optimization in several other key factors, especially aspects of the curriculum and benchmarking. In detail, various follow-up steps need to be carried out, such as the identification of several aspects of curriculum improvement and the OBE-based learning process (Outcome Base Education), evaluation of student learning and skills and overall evaluation of practicum according to RSC standards.

Keywords: Accreditation, Chemistry, Royal Society of Chemistry 


\section{Pendahuluan}

Revolusi industri telah menghasilkan pertumbuhan ekonomi, peningkatan produktivitas, dan kemajuan kesejahteraan. Selain itu negara-negara yang mengadopsinya memberikan dampak positif berupa munculnya layanan dan barang-barang berkualitas tinggi (Morrar at.al, 2017). Perubahan ini berdampak pula pada pengelolaan mutu pendidikan tinggi. Institusi pendidikan tinggi semakin di bawah tekanan publik untuk menunjukkan kualitas pendidikan dengan cara mengimplementasikan mekanisme kualitas dalam setiap institusi (Cheng, 2016). Oleh karena itu upaya setiap Perguruan Tinggi (PT) untuk meningkatkan kualitas programnya menjadi sangat penting sehingga tetap relevan dengan perubahan zaman yang makin menantang.

Salah satu upaya untuk medapatkan pengakuan terhadap kualitas pengelolaan PT melalui proses akreditasi baik secara nasional maupun internasional. Penelitian terbaru menunjukkan bahwa akreditasi lebih berkontribusi pada perbaikan proses dan praktik di lembaga yang beroperasi selama 1-20 tahun dibandingkan dengan yang berfungsi selama lebih dari 41 tahun. Demikian pula, akreditasi memberikan kontribusi yang lebih besar selama proses akreditasi awal dibandingkan dengan akreditasi ulang. Selain itu, akreditasi memberikan kontribusi paling penting yang melekat pada hasil pembelajaran dan paling sedikit pada jumlah siswa yang lulus dari suatu program (Ulker \& Baqioglu, 2018).

Lembaga akreditasi internasional yang spesifik untuk Program Studi Kimia adalah Royal Society of Chemistry (RSC). RSC adalah badan akreditasi paling berpengaruh di dunia dengan lebih dari 54.000 anggota. Jurnal-jurnal kimia yang diterbitkan oleh RSC memiliki impact factor tertinggi di dunia. RSC juga telah menetapkan standar ambang batas yang harus dipenuhi agar program gelar Kimia dapat terakreditasi (Royal Society of Chemistry, 2012).

Oleh karena itu analisis mengenai kesiapan berbagai komponennya yang dipersyaratkan secara umum dan khusus menjadi sangat relevan untuk meningkatkan kualitas Program Studi Kimia. Melalui penelitian ini akan diidentifikasi potensi Program Studi (PS) kimia dari aspek akademik dan penggunaan teknologi informasi. Selain itu akan diperoleh informasi sejauh mana PS Kimia memiliki kesiapan secara proses sesuai dengan standar yang ditetapkan oleh RSC. 


\section{Metode}

Penelitian ini difokuskan pada PS Kimia Fakultas Sains dan Teknologi UIN Syarif Hidayatullah Jakarta. Wawancara langsung dilakukan pada: dosen, laboran, pengajar islam dan ilmu pengetahuan serta pakar di bidang pengembangan islam dan ilmu kimia. Menyebarkan kuosioner pembelajaran, bahan ajar dan proses penyelesaian tugas akhir pada seluruh stakeholder, mahasiswa, dosen.

Penelitian ini adalah tergolong kepada jenis penelitian pustaka (library research) (Sukardi, 2003), yang bertujuan mengumpulkan data atau informasi dengan bantuan bermacam-macam material yang terdapat di ruang perpustakaan, seperti jurnal, laporan hasil penelitian, majalah ilmiah, surah kabar, buku yang relevan, hasil-hasil seminar, artikel ilmiah yang belum dipublikasikan, data internet yang ada kaitannya dengan judul penelitian ini dengan cara menelaah dan menganalisa sumber-sumber itu, hasilnya dicatat dan dianalisis. Assesment dilakukan pada aspek Keluasan dan kedalaman isi mata kuliah, Skill laboratorium (practical skill), Skripsi (undergraduate project work), Skill terkait profesi (professional skill), dan sistem penilaian (assessment), dan Penjaminan mutu (Internal QA). Focus Group Discussion (FGD) merupakan suatu proses pengumpulan informasi mengenai suatu masalah tertentu yang sangat spesifik (Irwanto, 2006). FGD ini mendengarkan pendapat para ahli yang memiliki pengalaman dalam memikirkan pengembangan Integrasi UIN jakarta termasuk pada ahli bidang pengembangan ilmu kimia di Perguruan Tinggi termasuk diantaranya webinar dengan pembicara dari RSC Indonesia dan wakil Perguruan Tinggi di Indonesia yang telah diakreditasi oleh RSC (Gambar1).

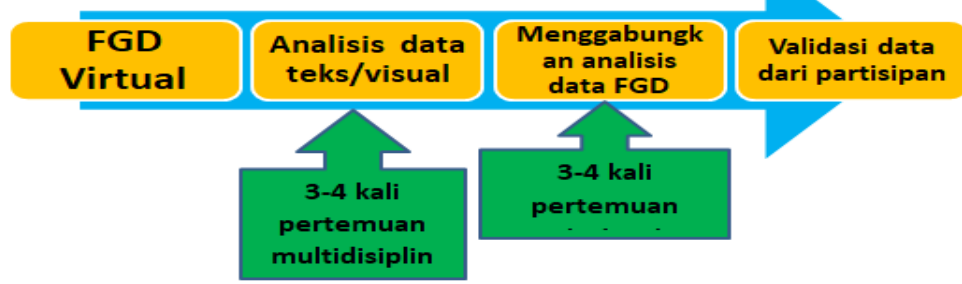

Gambar 1. Alur umum kegiatan penelitian

Analisis data dilaksanakan setelah data di lapangan berhasil dikumpulkan dan diorganisasikan dengan baik. Data hasil wawancara, studi pustaka, FGD dikumpulkan untuk mendapatkan kesimpulan 
akhir berupa: Hasil identifikasi potensi dan desain hasil analisis potensi untuk proses implementasi sesuai standar yang ditetapkan oleh RSC dengan komponen integrasi keilmuan di era IR 4.0. Kemudian Sinkronisasi dengan standar yang dikeluarkan oleh Royal Society of Chemistry (RSC).

\section{Hasil Penelitian dan Pembahasan}

\section{Hasil Survey Akademik}

Proses pembelajaran merupakan salah satu proses yang penting dalam pelaksanaan Tri Dharma Perguruan Tinggi yang dalam pelaksanaannya dilakukan oleh dosen. Dalam melaksanakan kegiatan proses pembelajaran perlu pemantauan dan evaluasi agar apa yang dilaksanakan oleh dosen menjadi lebih terarah dan sesuai dengan standar yang telah ditetapkan diperguruan tinggi. Kegiatan Monitoring dan evaluasi (Monev) proses pembelajaran merupakan kegiatan yang dilakukan oleh unit penjaminan mutu di tingkat program studi (Gambar2).

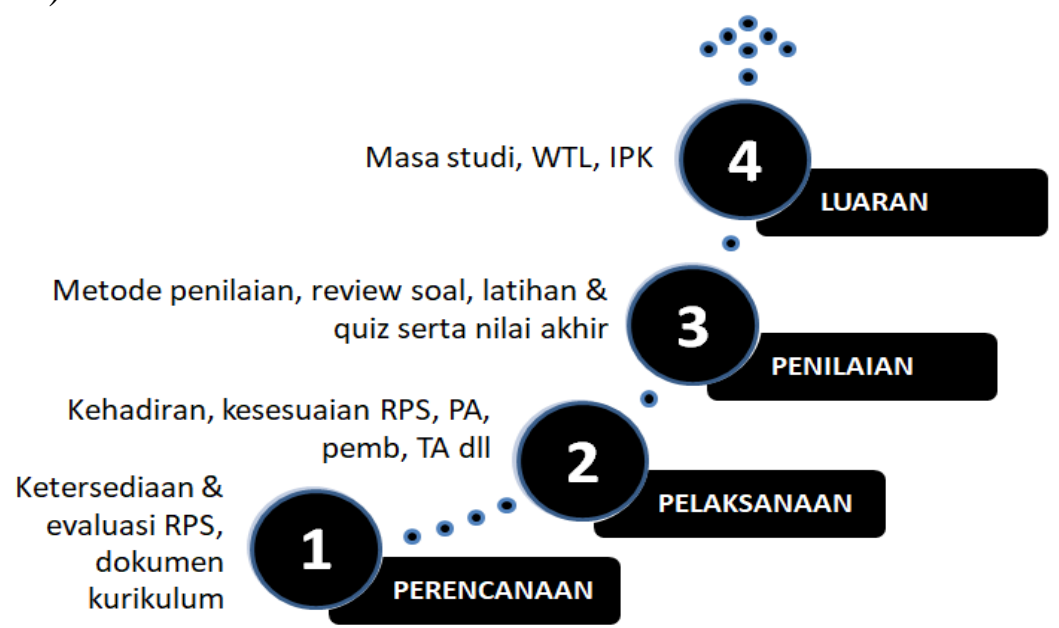

Gambar 2. Prinsip dan proses monitoring dan evaluasi akademik

Hasil studi pengaruh praktek Monitoring dan Evaluasi (M\&E) terhadap motivasi staf akademik memberikan kesimpulan akhir dalam studinya tentang pengaruh praktik merekomendasikan agar pembuat kebijakan merancang kebijakan tentang $\mathrm{M}$ \& E, yang akan memandu semua pihak dalam mengendalikan program (Niyivuga dkk, 2019). Selain itu ada sejumlah poin kuat agar program studi sesuai dengan tujuannya, mahasiswa harus dilibatkan dalam proses pengambilan 
keputusan (Rivza dkk, 2015). Pada saat yang sama, proses ini dapat memberikan pemahaman terhadap situasi perkembangan perguruan tinggi secara ilmiah, dan memberikan dasar bagi keputusan makro departemen administrasi Pendidikan (Li dkk, 2017).

Selajutnya dikemukakan pula bahwa bahwa proses monev fakultas yang berorientasi pada perbaikan, dapat menghasilkan hasil yang positif, bahkan dapat memperkuat hubungan profesional dengan organisasi (Shah \& Nair, 2012). Sebaliknya, ketika monev dianggap sebagai pengendalian, maka akan menyebabkan tekanan dan ketegangan yang dapat merusak motivasi karyawan (Zhang, 2008). Oleh karena itu merekomendasikan agar pembuat kebijakan merancang kebijakan tentang monev yang akan memandu para pimpinan dalam proses monev (Niyivuga dkk, 2019)

Survey pelayanan akademik yang menyediakan 5 alternatif jawaban yang dapat pilih, yaitu: $1=$ Sangat Tidak Setuju, $2=$ Tidak Setuju, $3=$ Netral, $4=$ Setuju, dan $5=$ Sangat Setuju, dilakukan terhadap 143 responden dengan sebaran responden sebagai berikut:

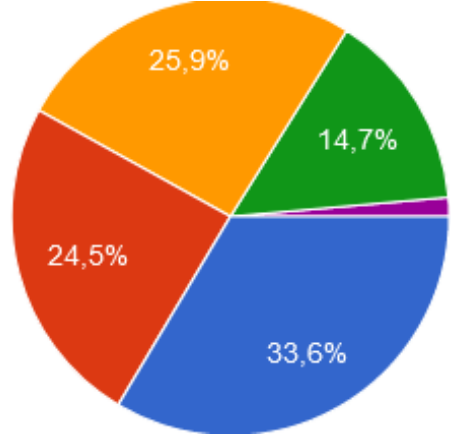

Responden berasal dari mahasiswa semester 2, 4, 6, 8 dan 10 yang tersebar diberbagai kelas di PS Kimia. Sementara itu, aspek penilaian pada 6 aspek seperti 1 . Tangibles, $\quad 2 . \quad$ Reliability, 3. Responsiveness, 4. Assurance, 5. Empathy dan 6. Kemampuan Penggunaan Teknologi.

Dilihat dari aspek responden yang berpartisipasi dalam angket ini maka cukup representatif. Mahasiswa yang berpartisipasi telah mewakili semua semester yang berlangsung pada saat itu atau sekitar $32 \%$.

Proses yang menjaga agar penjaminan ini secara konsisiten dilakukan adalah proses pengawasan (monitoring) dan evaluasi secara internal yaitu di dalam proses tersebut memuat kegiatan audit, asesmen dan evaluasi. Kegiatan ini walaupun secara teori dipisahpisah, namun secara praktis tidak dipisahkan antara satu dengan yang lain (Hedwig, 2006)

Terdapat lima faktor yang menentukan kualitas pelayanan jasa meliputi: 1) tangible (bukti langsung) mencakup fasilitas fisik, 
perlengkapan, pegawai, dan sarana komunikasi; 2) reliability (reliabilitas), yaitu kemampuan memberikan pelayanan yang dijanjikan dengan segera, akurat, dan memuaskan; 3) responsiveness (daya tanggap), yaitu keinginan staf membantu para pelanggan dan memberikan layanan dengan tanggap; 4) assurance (jaminan), mencakup pengetahuan, kompetensi, kesopanan, dan sifat dapat dipercaya yang dimiliki staf, bebas dari bahaya, resiko, atau keraguraguan; (5) empathy (empati), meliputi kemudahan dalam menjalin relasi, komunikasi yang baik, perhatian pribadi, dan pemahaman atas kebutuhan individu para pelanggan (Kotler, 2000).

\section{TANGIBLES, Sarana pendidikan - Alat Perkuliahan, Media Pengajaran dan Prasarana Pendidikan.}

Hasil analisis terhadap terhadap rata-rata aspek tangibles menunjukkan bahwa sebagian besar berada pada skor 3,1-3,6. Namun pada aspek ruang kuliah sejuk dan nyaman berada pada skor 2,8 (Gambar 3). Oleh karena itu aspek ini perlu mendapatkan perhatian untuk perbaikan di masa depan.
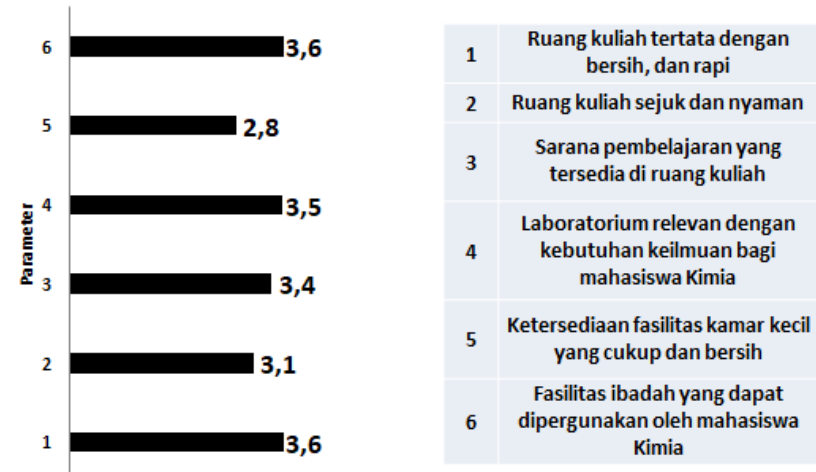

Gambar 3. Data rata-rata aspek tangibles

Hasil penelitian lain menyatakan bahwa besarnya pengaruh bukti fisik (tangible) terhadap kepuasan mahasiswa menunjukkan hasil yang sudah baik dengan demikian dapat disimpulkan bahwa jika bukti fisik (tangible) ditingkatkan maka akan menimbukan kontribusi kepuasan mahasiswa yang lebih maksimal lagi (Juhama \& Mulyawan, 2015).

\section{RELIABILITY, kehandalan dosen, staf Akademik}

Hasil analisis terhadap terhadap rata-rata aspek reliability menunjukkan bahwa sebagian besar berada pada skor 3,6-4,2. Namun pada aspek pada point 1,2 , 4, dan 5 berada di bawah skor 4,0 
(Gambar 4). Meskipun masih di skor yang cukup baik namun aspekaspek tersebut khusus pengembalian tugas (point 4) dan ketepatan dosen masuk kelas (point 5) perlu mendapatkan perhatian karena kedua aspek tersebut khususnya memiliki keterkaitan dengan persyaratan RSC untuk akreditasi internasional.
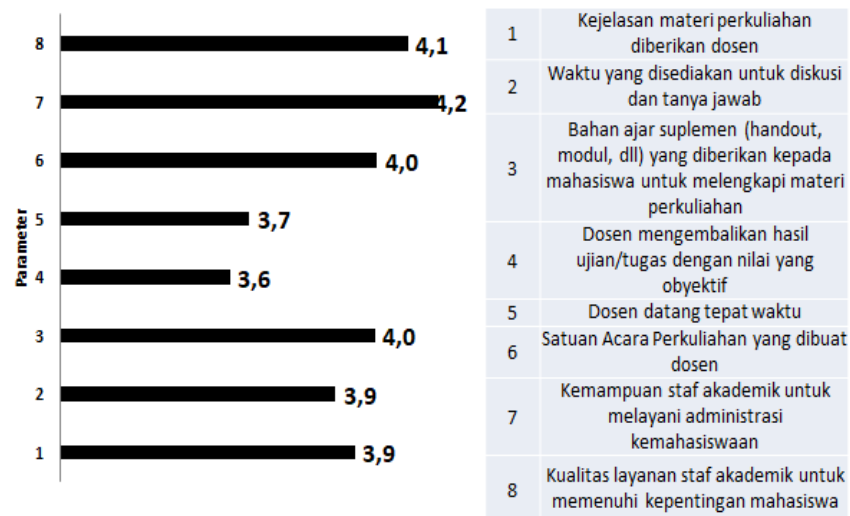

Gambar 4. Data rata-rata aspek reliability.

Besarnya pengaruh keandalan (reliability) terhadap kepuasan mahasiswa menunjukkan hasil yang sudah baik dengan demikian dapat disimpulkan bahwa jika keandalan (reliability) ditingkatkan maka akan meningkatkan kepuasan mahasiswa (Juhama \& Mulyawan, 2015).

\section{RESPONSIVENESS, Sikap tanggap}

Hasil analisis terhadap terhadap rata-rata aspek responsiveness menunjukkan bahwa sebagian besar berada pada skor 3,5-3,9. Namun pada aspek pada point 3 berada di bawah skor terendah 3,5 (Gambar 5). Meskipun masih di skor yang cukup baik namun aspek bantuan prodi jika mendapatkan masalah akademik perlu mendapatkan perhatian karena aspek ini memiliki keterkaitan dengan persyaratan RSC untuk akreditasi internasional.

Hasil penelitian lain menyatakan bahwa besarnya pengaruh daya tanggap (responsiveness) terhadap kepuasan mahasiswa menunjukkan hasil yang sudah baik dengan demikian dapat disimpulkan bahwa jika daya tanggap (responsiveness) ditingkatkan maka akan meningkatkan kepuasan mahasiswa (Juhama \& Mulyawan, 2015). 


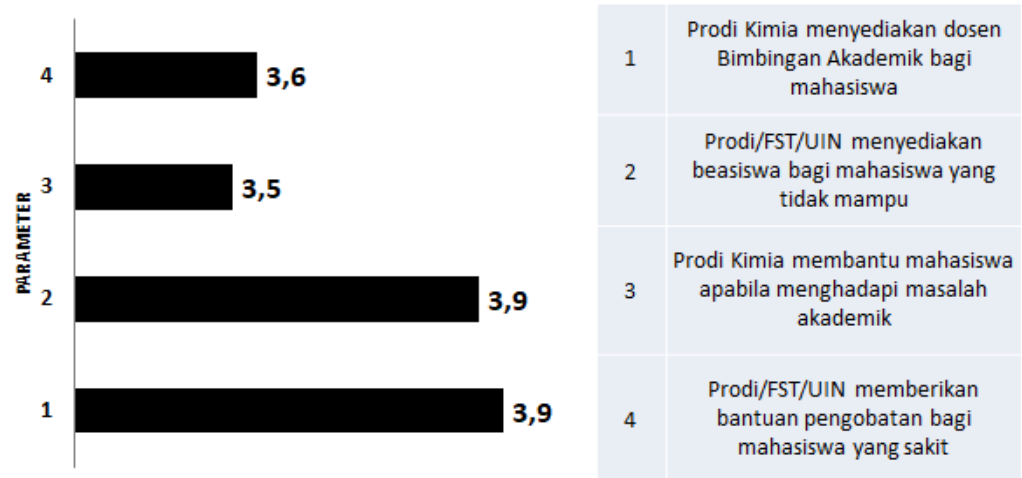

Gambar 5. Data rata-rata aspek responsiveness

4. ASSURANCE, Perlakuan pada mahasiswa

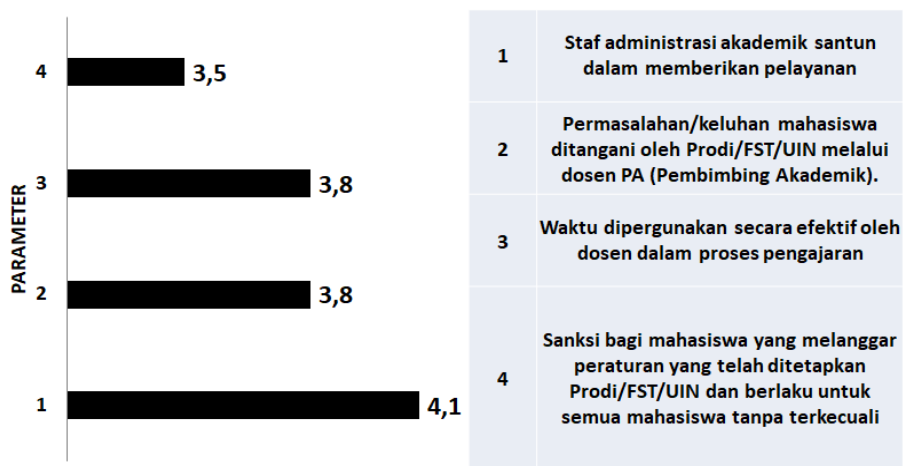

Gambar 6. Data rata-rata aspek assurance

Hasil analisis terhadap terhadap rata-rata aspek assurance menunjukkan bahwa sebagian besar berada pada skor 3,5-4,1. Namun pada aspek pada point 4 berada di bawah skor terendah 3,5 (Gambar 6). Meskipun masih di skor yang cukup baik namun aspek penegakkan peraturan tanpa diskriminasi perlu mendapatkan perhatian.

Selain itu dinyatakan bahwa besarnya pengaruh kepastian (assurance) terhadap kepuasan mahasiswa menunjukkan hasil yang sudah baik dengan demikian dapat disimpulkan bahwa jika kepastian (assurance) ditingkatkan maka akan meningkatkan kepuasan mahasiswa (Juhama \& Mulyawan, 2015). 


\section{EMPATHY, Pemahaman terhadap kepentingan mahasiswa}

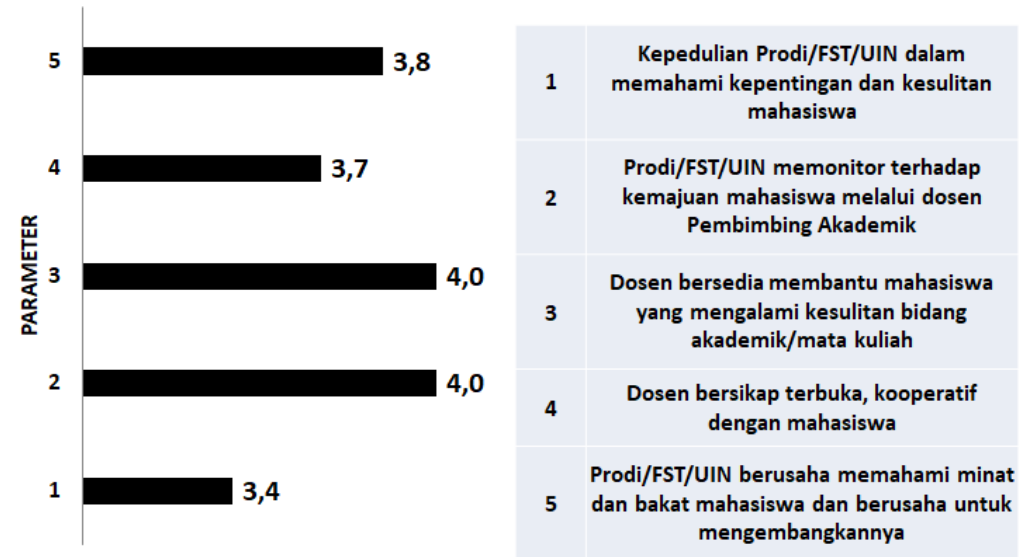

Gambar 7. Data rata-rata aspek empathy

Hasil analisis terhadap terhadap rata-rata aspek emphathy menunjukkan bahwa sebagian besar berada pada skor 3,4-4,0. Namun pada aspek pada point 1 berada di bawah skor terendah 3,4 (Gambar 7). Meskipun masih di skor yang cukup baik namun aspek kepedulian prodi/FST/UIN dalam memahami kepentingan dan kesulitan mahasiswa perlu mendapatkan perhatian karena aspek ini memiliki keterkaitan dengan persyaratan RSC untuk akreditasi internasional.

Hasil studi lain menyatakan bahwa besarnya pengaruh empati (empathy) terhadap kepuasan mahasiswa menunjukkan hasil yang kurang baik dengan demikian dapat disimpulkan bahwa empati (empathy) tidak terlalu mempengaruhi kepuasan mahasiswa (Juhama \& Mulyawan, 2015).

\section{KEMAMPUAN PENGGUNAAN TEKNOLOGI}

Kemampuan dosen-dosen prodi juga dalam penggunaan teknologi dalam kegiatan pembelajaran juga cukup baik karena berada di skor 3,9-4,1 sehingga dapat mengikuti perkembangan zaman pada era revolusi 4.0 (Gambar 8). 

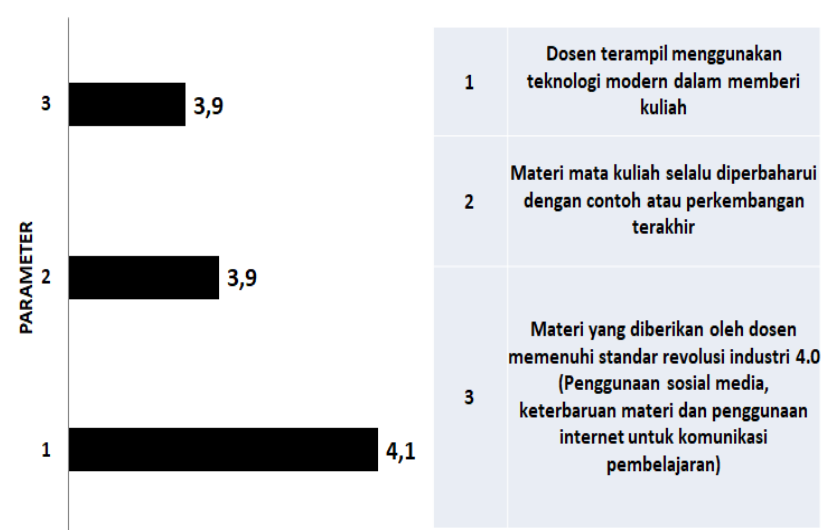

Gambar 8. Data rata-rata kemampuan penggunaan teknologi

\section{Pelaksanaan Praktikum}

Program Studi kimia memiliki sejumlah laboratorium meliputi laboratorium kimia organik, laboratorium anorganik, Laboratorium kimia dasar, laboratorium biokimia serta laboratorium pangan dan lingkungan yang terpusat di Pusat Laboratorium Terpadu (PLT).

Secara umum pengelolaan praktikum telah dilakukan dengan baik karena pola pelaksanaan praktikum masih sesuai dengan seharusnya. Akan tetapi dari setiap item yang disurvey masih cukup besar item yang belum sesuai terutama pada aspek pemeriksaan dan pengembalian laporan praktikum tepat waktu, pelaksanaan praktikum tepat waktu, dan ketersedian waktu untuk kegiatan praktikum (Gambar 9). Beberapa item yang disoroti ini cukup penting karena berkaitan dengan aspek yang dinilai dalam akreditasi internasional misalnya Royal Society of Chemistry (RSC).

Program praktikum berkualitas tinggi (Eyers, 2004) jika memenuhi syarat berikut:

- Mengintegrasikan pengetahuan teoritis dan praktik profesional yang mengitegrasikan tiga domain pendidikan.

- Mengartikulasikan dengan jelas dan progresif tahapan untuk pengembangan memperoleh pengetahuan, keterampilan, atribut dan disposisi dosen muda

- Memberikan pengalaman yang beragam dalam berbagai konteks Pendidikan kepada seluruh mahasiswa.

- Fleksibel dan memberi semangat inovasi

- Melibatkan evaluasi berkelanjutan dan tanggapan dari berbagai sisi. 
Penjelasan aturan aturan Safety and Security selama melakukan praktikum

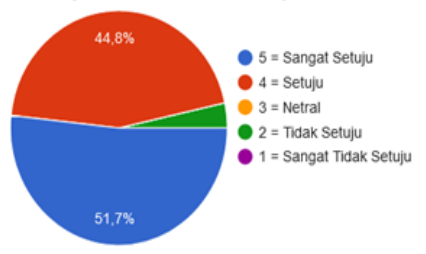

Pemeriksaan \& Pengembalian laporan praktikum tepat waktu

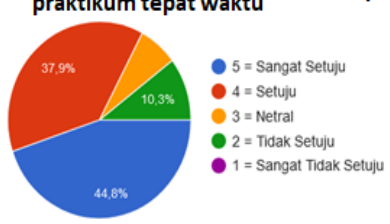

Praktikum dilaksanakan tepat waktu (masuk dan

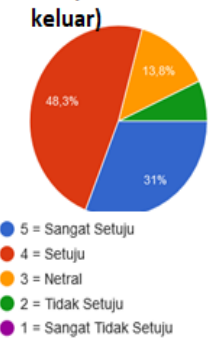

Pengawasan Praktikum oleh Dosen

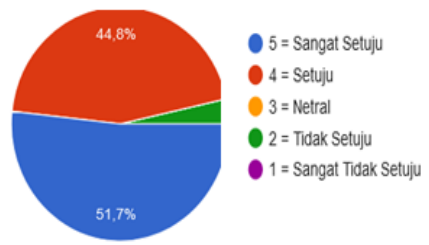

Waktu yang disediakan untuk pelaksanaan kegiatan praktikum sudah memenuhi

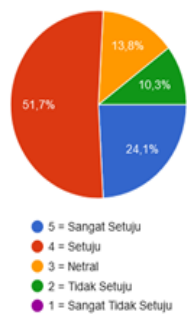

Gambar 9. Data persepsi pelaksanaan praktikum kimia.

\section{Kualifikasi Pendidikan S3 DT (Dosen Tetap)/DTPS (Dosen Tetap} Program Studi) dan kecukupan Dosen Tetap.

PS telah menempatkan atau menugaskan dosen yang memiliki kualifikasi dan kompetensi yang sesuai dengan kualifikasi dan kompetensi bidang tugasnya agar tujuan program studi dapat tercapai. Saat ini, jumlah DTPS Kimia sebanyak 14 orang dan telah mencapai pendidikan S3 sebanyak 5 orang dan sebanyak 8 orang masih bergelar magister, 1 diantaranya sedang menjalankan tugas belajar S3. Sebanyak 47\% DTPS Kimia bergelar Doktor dan 53\% masih bergelar Master. Kualifikasi dosen tetap PS Kimia telah memenuhi Keputusan Menteri Agama RI nomor 582 tahum 2018 tentang standar pelayanan minimum pada UIN Syarif Hidayatullah Jakarta.

Jumlah dosen terkait proses pengajaran dan pembimbingan telah mencukupi sebanyak 27 dosen, dibuktikan dengan rerata beban pengajaran yang tidak melebihi jumlah sks Beban Kerja Dosen sebagaimana diatur dalam peraturan BKD pokok dan tambahan. Kecukupan dimaksud karena dalam pengajaran selain Dosen tetap yang berhomebase di Fakultas Sains dan Teknologi, juga terdapat dosen tetap UIN Syarif Hidayatullah Jakarta yang mempunyai homebase di Program Studi lain di UIN Syarif Hidayatullah Jakarta. Selain itu adapula bantuan lain dari pihak industri atau praktisi sebagai pembimbing skripsi atau Praktek Kerja Lapangan (PKL). 


\section{Pengakuan/rekognisi atas kepakaran/prestasi/kinerja DTPS.}

Pengakuan/rekognisi atas kepakaran/prestasi/kinerja DTPS di PS Kimia FST UIN Syarif Hidayatullah Jakarta yang diterima dalam 3 tahun terakhir telah diakui dari beberapa kegiatan di tingkat Nasional dan Internasional dalam berbagai kegiatan diantaranya sebagai reviewer penelitian dosen di IAIN Kendari, Auditor Pangan Halal di LPPOM MUI, Reviewer Jurnal Terakreditasi SINTA, reviewer Jurnal bereputasi internasional, Ketua Forum dekan PTKIN dan Ketua HKI, narasumber penulisan karya Ilmiah UIN Semarang, dan narasumber studium General (Gambar 10).

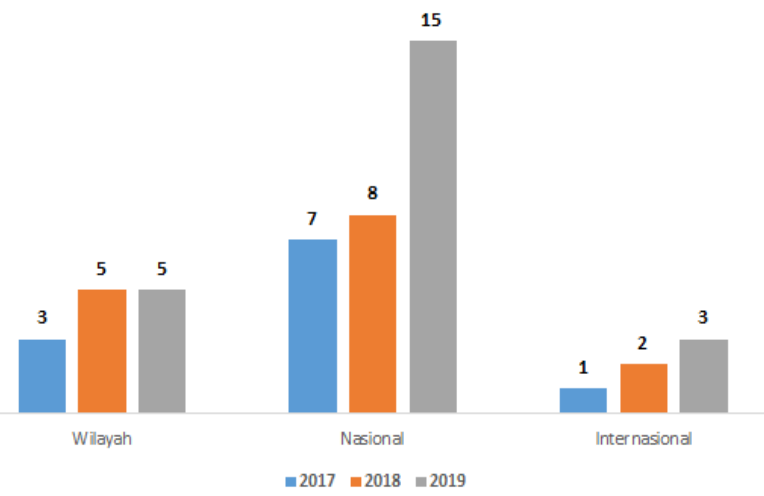

Gambar 10. Perkembangan rekognisi DTPS selama 3 tahun terakhir

\section{Data, analisis dan Benchmark menuju akreditasi RSC}

RSC telah melakukan akreditasi ke berbagai perguruan tinggi yang ada di dunia. Reputasi RSC dapat dilihat pula pada jurnal yang diakreditasi oleh RSC memiliki Impact Factor yang tinggi (Roto, (2020).

Pada proses akreditasi di RSC yang paling penting adalah Apakah dokumen yang dibuat sudah sesuai dengan arahan yang dipersyaratkan RSC? Dokumen yang disubmit kemudian mengalami proses oleh 3 Peer Review yaitu 1. Administration spesialist bermarkas di London yang akan selalu mengecek dokumentasi yang diberikan oleh PS, 2. Komite Akreditasi dan Validasi RSC yang bertanggung jawab untuk meninjau aplikasi, menerapkan kriteria dan membuat penilaian untuk akreditasi dan 3. Dewan RSC menunjuk anggota komite dan penguji eksternal dari kalangan akademisi dan profesional yang tinggi. 
Tabel 1. Kriteria Kunci, Potensi dan tindak lanjut PS Kimia menuju akreditasi RSC

\begin{tabular}{|c|c|c|c|}
\hline Kegiatan & Kondisi PS Kimia & Tindak Lanjut & $\begin{array}{c}\text { Standar minimal } \\
\text { RSC }\end{array}$ \\
\hline
\end{tabular}

1. Keluasan dan kedalaman ilmu yang diajarkan. Bukti kajian dari tiga cabang utama kimia yang diberikan pada beberapa semester selama di perguruan tinggi dan luaran Prodi harus mencakup pemahaman yang luas tentang kimia dengan kemampuan memecahkan masalah pada ambang batas kompetensi

2. Kedalaman (Materi). Hal ini tercermin dalam silabus lengkap sampai contoh soal lengkap yang harus disertakan pada laporan. Penilaian, dengan bukti kemampuan menerapkan pengetahuan dan memecahkan masalah. Program harus dibangun di atas basis pengetahuan untuk memungkinkan mahasiswa menghargai perkembangan, di beberapa area, di garis depan disiplin ilmu.

Kedalaman: terkait dengan No 1. Seperti mutu soal ujian akan benar-benar di nilai, sehingga jika ada yang kurang maka harus konsultasi, misalnya kurang dalam memberikan materi akan diminta untuk dilengkapi. Yang akan dilihat pertama: Silabus, RPS/modul handbook, contoh soal ujian dan mutu jawaban mahasiswa.

3.Title: Jumlah jam dan pembagian dalam kurikulum berdasarkan kualifikasi dan porsi MK (Matakuliah) yang akan memperlihatkan konsentrasi PS tersebut. Judul program harus menunjukkan konten dan mengatasi asumsi yang akan dibuat oleh pemberi kerja tentang kemampuan lulusan berdasarkan judul.

\begin{tabular}{|c|c|c|c|}
\hline $\begin{array}{l}\text { Evaluasi skill } \\
\text { Laboratorium }\end{array}$ & $\begin{array}{l}17 \text { Jenis Praktikum, } \\
\text { @ } 2 \text { jam (Terlihat } \\
\text { pada distribusi MK } \\
\text { Kurikulum 2020) }\end{array}$ & 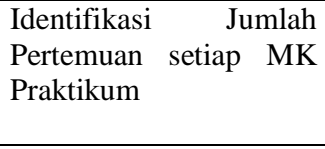 & $\begin{array}{lr}\text { Minimal } & 300 \quad \text { jam, } \\
\text { lengkap } & \text { dengan } \\
\text { modulnya } & \text { (Practical } \\
\text { Skill) } & \\
\end{array}$ \\
\hline $\begin{array}{l}\text { Evaluasi } \\
\text { Praktikum }\end{array}$ & $\begin{array}{l}\text { Hampir tidak ada } \\
\text { praktikum } \\
\text { Double, Wong } \\
\text { safety and Security } \\
\text { dilaksanakan setiap } \\
\text { tahun oleh di awal } \\
\text { masuk }\end{array}$ & $\begin{array}{l}\text { Identifikasi kembali } \\
\text { Topik-topik praktikum, } \\
\text { diperlukan pengayaan } \\
\text { workshop-workshop } \\
\text { terkait skill } \\
\text { laboratorium }\end{array}$ & $\begin{array}{l}\text { Tidak boleh ada } \\
\text { praktikum yang } \\
\text { doubel dilaksanakan. } \\
\text { Adanya workshop- } \\
\text { workshop kaitannya } \\
\text { dengan Skill misalnya } \\
\text { Workshop Safety and } \\
\text { Security untuk } \\
\text { mahasiswa baru, } \\
\text { workshop-workshop } \\
\text { instrumentasi }\end{array}$ \\
\hline $\begin{array}{l}\text { Penilaian } \\
\text { Praktikum }\end{array}$ & $\begin{array}{l}\text { Telah ada evaluasi } \\
\text { berbentuk quiz } \\
\text { maupun praktek }\end{array}$ & $\begin{array}{l}\text { Identifikasi jumlah } \\
\text { pertemuan, responsi } \\
\text { berbentuk praktek }\end{array}$ & $\begin{array}{l}\text { Minimal } 10 \text { kali } \\
\text { pertemuan, evaluasi } \\
\text { juga berbeda dengan } \\
\text { model evaluasi } \\
\text { perkuliahan, } \\
\text { responsi tapi bentuk } \\
\text { praktek, bukan bentuk } \\
\text { soal kuis }\end{array}$ \\
\hline $\begin{array}{l}\text { Evaluasi } \\
\text { Asisten } \\
\text { Praktikum }\end{array}$ & $\begin{array}{l}\text { Masih ada asisten } \\
\text { yang merupakan } \\
\text { mahasiswa tingkat } \\
\text { akhir, namun setiap }\end{array}$ & 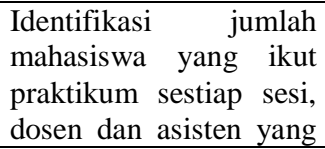 & $\begin{array}{lr}\text { Asisten } & \text { tidak } \\
\text { membolehkan kakak } \\
\text { tingkat, namun dapat } \\
\text { menggunakan }\end{array}$ \\
\hline
\end{tabular}




\begin{tabular}{|c|c|c|c|}
\hline & $\begin{array}{l}\text { praktikum telah } \\
\text { diampu oleh dosen } \\
\text { masing-masing } \\
\text { namun jumlahnya } \\
\text { masih sekitar } 25 \\
\text { mahasiswa }\end{array}$ & $\begin{array}{l}\text { mengampu di setiap sesi } \\
\text { tersebut, apakah telah } \\
\text { memenuhi syarat RSC? }\end{array}$ & $\begin{array}{l}\text { mahasiswa S2 yang } \\
\text { telah lulus S1, } 1 \\
\text { Asisten minimal } 20 \\
\text { mahasiswa }\end{array}$ \\
\hline $\begin{array}{l}\text { Sarana } \\
\text { Instrumen } \\
\text { Praktikum }\end{array}$ & $\begin{array}{l}\text { Memiliki GC-MS, } \\
\text { Spekrofotometer UV- } \\
\text { Vis, FTIR, XRD }\end{array}$ & $\begin{array}{l}\text { Identifikasi alat yang } \\
\text { dikaitkan dengan } \\
\text { keperluan pencapaian } \\
\text { kompetensi, jika belum } \\
\text { terpenuhi dapat } \\
\text { dilakukan MoU dengan } \\
\text { beberapa instansi lain } \\
\text { yang memiliki intrumen } \\
\text { tersebut. }\end{array}$ & $\begin{array}{l}\text { Representatif untuk } \\
\text { pencapaian } \\
\text { kompetensi dapat } \\
\text { dimiliki sendiri atau } \\
\text { melalui } \\
\text { sehingga moU } \\
\text { diakses mahasiswa }\end{array}$ \\
\hline
\end{tabular}

4.Metode assesment: Mulai cara mengakses mahasiswa pada kegiatan praktikum sampai kegiatan lainnya. Penilaian harus bervariasi, sesuai dan ketat, dan menuntut mahasiswa untuk menerapkan pengetahuan mereka dan memecahkan masalah. Metode Assesment: Test atau Quiz, Tidak hanya mengandalkan ujian, mengerjakan soal secara bersama, teaching the roll, presentasi, penilaian tugas akhir, penilaian PKL.

\begin{tabular}{|c|c|c|c|}
\hline $\begin{array}{l}\text { Evaluasi } \\
\text { Penugasan }\end{array}$ & $\begin{array}{l}\text { Sudah Tercantum } \\
\text { dalam setiap RPS }\end{array}$ & $\begin{array}{l}\text { Perlu rincian pada } \\
\text { setiap penugasan Quiz, } \\
\text { presentasi, atau } \\
\text { penugasan yang lain }\end{array}$ & $\begin{array}{l}\text { Setiap MK memiliki } \\
\text { standar penugasan }\end{array}$ \\
\hline $\begin{array}{l}\text { Evaluasi } \\
\text { Beban Belajar }\end{array}$ & $\begin{array}{l}\text { Melalui agenda } \\
\text { perkuliahan }\end{array}$ & $\begin{array}{l}\text { Dipastikan bahwa } \\
\text { agenda perkuliahan di } \\
\text { isi secara lengkap sesuai } \\
\text { dengan jam yang } \\
\text { direncanakan }\end{array}$ & $\begin{array}{lr}\text { Mahasiswa } & \text { harus } \\
\text { terpenuhi } & \text { jam } \\
\text { belajarnya } & \end{array}$ \\
\hline $\begin{array}{l}\text { Evaluasi } \\
\text { Belajar dan } \\
\text { skill } \\
\text { mahasiswa }\end{array}$ & Belum dilakukan & $\begin{array}{l}\text { Perlu dibuat rubriknya } \\
\text { sehingga memudahkan } \\
\text { pendistribusian ke } \\
\text { setiap dosen }\end{array}$ & 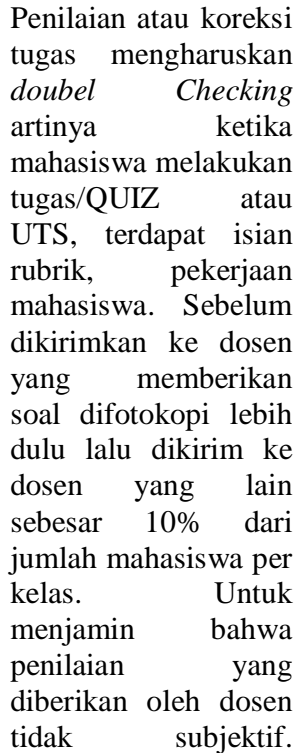 \\
\hline
\end{tabular}




\begin{tabular}{|c|c|c|c|}
\hline & & & $\begin{array}{l}\text { Kelengkapan berupa } \\
\text { modul dan jawaban } \\
\text { soal. }\end{array}$ \\
\hline Tutorial & $\begin{array}{l}\text { Masih dilakukan oleh } \\
\text { kakak tingkat dan } \\
\text { belum terjadwal } \\
\text { dengan baik }\end{array}$ & $\begin{array}{l}\text { Perlu tutorial oleh } \\
\text { dosen-dosen praktikum } \\
\text { atau teori }\end{array}$ & 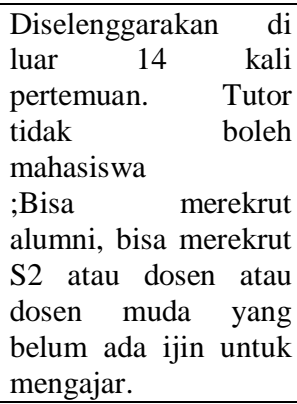 \\
\hline $\begin{array}{l}\text { Evaluasi } \\
\text { Beban SKS } \\
\text { pada Kimia } \\
\text { Inti: Kimia } \\
\text { Organik, } \\
\text { Anorganik, } \\
\text { Kimia Fisika. }\end{array}$ & $\begin{array}{l}\text { Terlampir pada } \\
\text { distribusi matakuliah } \\
\text { dalam kurikulum }\end{array}$ & $\begin{array}{l}\text { Perlu dilakukan } \\
\text { perhitungan secara riil }\end{array}$ & $\begin{array}{l}\text { Mensyaratkan jumlah } \\
\text { SKS dan durasinya } \\
\text { terpenuhi. }\end{array}$ \\
\hline $\begin{array}{l}\text { Evaluasi } \\
\text { Tugas Akhir } \\
\text { (Final } \\
\text { Project) }\end{array}$ & $\begin{array}{l}\text { Tugas Akhir } 6 \text { SKS, } \\
\text { seminar } 1 \text { SKS }\end{array}$ & $\begin{array}{lr}\text { Perlu } & \text { dilakukan } \\
\text { perhitungan } & \text { ulang dan } \\
\text { konsultasi } & \text { dengan } \\
\text { advisor RSC } & \text { Indonesia }\end{array}$ & 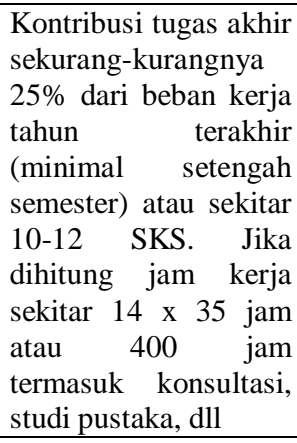 \\
\hline
\end{tabular}

5. Placement: Bagaimana mendidik mahasiswa di luar kampus dengan durasi waktu minimal 1 bulan. Hal ini tercermin misalkan pada kegiatan Praktek Kerja Lapangan (PKL) dengan durasi waktu misalnya minimal 1 bulan (misal Merdeka Belajar) 8 x 20 hari yang setara dengan 300 jam. Setiap penempatan eksternal harus tunduk pada penilaian terhadap kriteria eksplisit dan menuntut universitas untuk melaksanakan kontrol dan pengawasan terhadap mahasiswanya.

\begin{tabular}{|l|l|l|l|}
\hline $\begin{array}{l}\text { Skill } \\
\text { Penempatan }\end{array}$ & $\begin{array}{l}\text { PKL dan KKN sudah } \\
\text { dilakukan selama 1 } \\
\text { bulan }\end{array}$ & $\begin{array}{l}\text { Perlu ada MoU } \\
\text { penempatan } \\
\text { mahaasiswa PKL, } \\
\text { metode penilaian dan } \\
\text { monitoring kegiatan di } \\
\text { tempat PKL }\end{array}$ & $\begin{array}{l}\text { Jaminan penempatan } \\
\text { PKL melalui MoU, } \\
\text { dimonitor oleh dosen, } \\
\text { dan memiliki standar } \\
\text { penilaian tertentu }\end{array}$ \\
\hline $\begin{array}{l}\text { Profesional } \\
\text { (Generill }\end{array}$ & $\begin{array}{l}\text { Telah dilakukan } \\
\text { melalui berbagai } \\
\text { kegiatan-kegiatan } \\
\text { kemahasiswaaan } \\
\text { secara mandiri }\end{array}$ & $\begin{array}{l}\text { Perlu identifikasi } \\
\text { kegiatan-kegiatan } \\
\text { tersebut atau dapat pula } \\
\text { difasilitasi on oleh } \\
\text { Program Studi }\end{array}$ & $\begin{array}{l}\text { Diperlukan dokumen } \\
\text { yang menjelaskan } \\
\text { Skill yang diperlukan } \\
\text { ketika terjun ke dunia } \\
\text { kerja Misalnya: }\end{array}$ \\
\hline
\end{tabular}




\begin{tabular}{|c|c|c|c|}
\hline & & & $\begin{array}{lr}\text { Manajemen } & \text { Waktu, } \\
\text { Kerja dalam } & \text { Tim, } \\
\text { kemampuan } & \\
\text { komunikasi } & \text { oral, } \\
\text { kemampuan } & \\
\text { komunikasi } & \text { tertulis } \\
\text { Kemampuan } & \text { Literasi } \\
\text { Kimia } & \\
\end{array}$ \\
\hline Benchmark & $\begin{array}{l}\text { Belum menjadi } \\
\text { kegiatan yang } \\
\text { terjadwal }\end{array}$ & $\begin{array}{l}\text { Perlu diagendakan } \\
\text { benchmark ke beberapa } \\
\text { PT di dalam Negeri } \\
\text { terutama yang telah } \\
\text { terakreditasi RSC. }\end{array}$ & $\begin{array}{lr}\text { RSC memberikan } \\
\text { apresiasi dan nilai } \\
\text { tinggi PT yang sering } \\
\text { melaksanakan } \\
\text { Benchmark ke PT lain } \\
\text { yang lebih tinggi } \\
\text { rangkingnya untuk } \\
\text { pengembangan PS } \\
\text { artinya tidak musti PT } \\
\text { LuarNegeri. }\end{array}$ \\
\hline Sumber Daya & Cukup representatif & Cukup representatif & Representatif \\
\hline $\begin{array}{l}\text { Daya Dukung } \\
\text { Institusi }\end{array}$ & Cukup representatif & Cukup representatif & Representatif \\
\hline \multicolumn{4}{|c|}{$\begin{array}{l}\text { 6. Penjaminan Mutu: Kalau sistim penjaminan mutu berjalan baik maka akan lebih } \\
\text { mudah bekerja dengan RSC. Ketika visitasi maka asesor RSC pertama kali akan } \\
\text { diskusi dengan kantor penjaminan mutu. Bagaimana menyeleksi mahasiswa, } \\
\text { Bagaimana mengecek kemajuan belajar mahasiswa, bagaimana mengukur } \\
\text { kompetensi mahasiswa atau ELO (Expected Learning Outcome). Sumber daya } \\
\text { yang dikhususkan untuk suatu program harus menyediakan lingkungan yang } \\
\text { mendukung yang sesuai bagi mahasiswa sehingga memungkinkan keberhasilan } \\
\text { mencapai hasil pembelajaran yang telah dijanjikan. }\end{array}$} \\
\hline $\begin{array}{l}\text { Penjaminan } \\
\text { Mutu }\end{array}$ & $\begin{array}{lr}\text { EDOM } & \text { Survey KBM, } \\
\text { AMI, rekrutmen } \\
\text { mahasiswa, } \quad \text { SIQA } \\
(\text { Sistem } \quad \text { Informasi } \\
\text { Quality Assurance) }\end{array}$ & $\begin{array}{lr}\text { Perlu ditambahkan } \\
\text { tentang } \\
\text { ketercapaian CPL dan } \\
\text { metode penilaian }\end{array}$ & $\begin{array}{l}\text { Berjalan dengan baik } \\
\text { dan sistematis serta } \\
\text { ketersediaan data }\end{array}$ \\
\hline
\end{tabular}

\section{Kesimpulan dan Implikasi}

Hasil penelitian menunjukkan bahwa secara umum PS kimia telah mengikuti perkembangan revolusi industri 4.0 yang terlihat dari sisi dukungan sumberdaya dengan kemampuan penggunaan teknologi informasi yang baik. Kriteria kunci akreditasi RSC juga telah dapat dicapai oleh PS Kimia, namun demikian perlu optimalisasi dalam beberapa faktor seperti penyesuaian kurikulum, proses pembelajaran berbasis OBE (Outcome Base Education), evaluasi belajar, skill mahasiswa, evaluasi praktikum sehingga sesuai dengan standar RSC. 
Tindaklanjut ini sangat penting untuk memastikan bahwa PS Kimia dapat mengajukan akreditasi internasional.

\section{Ucapan Terimakasih}

Penulis mengucapkan terimaksih kepada Lembaga Penelitian dan Pengabdian Masyarakat (LP2M) UIN Syarif Hidayatullah Jakarta melalui Pusat Penelitian dan Penerbitan yang yang telah membiayai penelitian ini. Dana yang digunakan pada tahun Anggaran 2020 melalui SK Kuasa Pengguna Anggaran UIN Syarif Hidayatullah Jakarta No Un.01/KPA/455/2020.

\section{Daftar Pustaka}

Agbor, J.M. (2011). The Relationship between Customer Satisfaction and Service Quality: a study of three Service sectors in Umeå

Cheng, M. (2016). Quality in Higher Education Developing a Virtue of Professional Practice University of Wolverhampton, UK. 2016. Sense Publisher. Rotterdam/Boston/Taipei

Eyers, V. (2004). Guidelines for Quality in the Practicum. National Institute for Quality Teaching and School Leadership. Australian

Hedwig, R. (2006). Monitoring dan Evaluasi Internal di Perguruan Tinggi yang telah menerapkan sistem penjaminan mutu. Jakarta: Graha Ilmu.

Irwanto. (2006). Focused Group Discussion (FGD): Sebuah Pengantar Praktis. Jakarta: Yayasan OborIndonesia

Juhana, D., \& Mulyawan, A. (2015). Pengaruh Kualitas Layanan Jasa Pendidikan Terhadap Kepuasan Mahasiswa Di Stmik Mardira Indonesia Bandung. Jurnal Ekonomi, Bisnis \& Entrepreneurship. 9(1), 1-15

Kotler, P. (2000). Marketing Management 9th edition. New Jersey. Prentice Hall International. Inc

Li, Y., Li, P., Zhu, F., \& Wang, R. 2017. Design of higher education quality monitoring and evaluation platform based on big data. 12th International Conference on Computer Science and Education (ICCSE). DOI: 10.1109/ICCSE.2017.8085513

Morrar, R., Arman, H., \& Mousa, S. (2017). 12 The Fourth Industrial Revolution (Industry 4.0): A Social Innovation Perspective. Technology Innovation Management Review. 7(11), 12-20. 
Niyivuga, B., Otara, A., \& Tuyishime, D. (2019). Monitoring and Evaluation Practices and Academic Staff Motivation: Implications in Higher Education Within Rwandan Context SAGE Open. DOI: 10.1177/2158244019829564 journals.sagepub.com/home/sgo

Rivza, B., Bikse, V., \& Brence, I. (2015). Evaluation of higher education study programmes and their development trends as drivers of regional growth. Procedia Economics and Finance 4th World Conference on Business, Economics and Management, 26, $643-650$ doi: 10.1016/S22125671(15)00804-7

Roto. (2020). RSC ACCREDITATION CRITERIA. Makalah acara Webinar Himpunan Kimia Indonesia (HKI) Pusat. Seminar Daring Ke-1 Himpunan Kimia Indonesia: Rekognisi Akreditasi Internasional.

Royal Society of Chemistry. (2012). RSC Accreditation of Degree Programmes [Online]. Available at: http://www.rsc.org/images/Accreditation\%20Criteria\%20January\% 202012_tcm18- 151306.pdf (Accessed: 01 June 2021)

Sukardi. (2003). Metodologi Penelitian Pendidikan Kompetensi dan Praktiknya. Yogyakarta: Bumi Aksara

Ulker, N., \& Bakioglu, A. (2018). An international research on the influence of accreditation on academic quality. Studies in Higher Education. 44(1):1-12. DOI:10.1080/03075079.2018.1445986

Zhang, J. (2008). Expectancy and university academics' motivation to participate in performance assessments (Masters' thesis). University of Oslo, Norway. Retrieved from http://tutkielmat.uta.fi/pdf/gradu03128.pdf.

http://kim.fst.uinjkt.ac.id/ 